\title{
The histology of erythema nodosum leprosum. Variant forms in New Guineans and other ethnic groups
}

\author{
D S RIDLEY, T H REA \& K P W J McADAM* \\ Hospital for Tropical Diseases, London; \\ University of Southern California School of Medicine; \\ Institute of Medical Research, Goroka, Papua New Guinea \\ Received for publication 8 August 1980
}

Summary The histology of erythema nodosum leprosum (ENL) shows some distinctive variations, which were considered in relation to ethnic groups in Papua New Guinea, Malaysia, Mexico and a miscellaneous group of ENL patients. In highland patients of Papua New Guinea the reaction involved the connective tissues of the dermis more than the lepromatous granuloma, and the chief features were oedema and fibrinoid necrosis followed by very heavy fibrosis. Infiltration of neutrophils was a subsidiary finding. In Malaysia, some of the features of the necrotizing form of ENL, previously described, were detectable fairly regularly even in less severe non-necrotizing lesions. In Mexican patients who developed ENL rather than the Lucio form of reaction, the ENL was of the classic type and did not differ from the ENL seen in the miscellaneous group.

ENL appears to be a complex of reactions whose form may perhaps be modified by ethnic factors as well as by the immune status within the spectrum.

\section{Introduction}

Clinically erythema nodosum leprosum (ENL) varies considerably in its severity and in the extent to which it causes systemic complications, but otherwise its skin lesions are recognizably similar. ${ }^{1}$ Histologically the classic form of ENL, essentially an acute inflammation superimposed on a lepromatous granuloma, is a well recognized entity, ${ }^{2,3,4}$ though among the Bantu the reaction was found to be more definitely subcutaneous ${ }^{2}$ than in the other two studies from India $^{3}$ and the Philippines. ${ }^{4}$ There are some significant variants of this pattern. An escharotic or necrotizing form of reaction found in south Vietnam ${ }^{5}$ and Malaysia $^{6}$ was considered to be a form of ENL rather than the Lucio form of

* Present address: Tuffs University School of Medicine, Boston, Massachusetts 02111. 
reaction which, despite some claims, has not been confirmed in patients other than those of Mexican or Central American origin. Another histologically divergent form of ENL is one that consists mainly in a disturbance of the dermal connective tissue rather than the granuloma. ${ }^{7}$ It is relatively uncommon, is often correlated clinically with a quite mild but otherwise typical form of ENL, or it may even be clinically non-reactive. It has, therefore, received little attention.

In the present paper we report an apparently unique group of cases of ENL of the connective tissue type in patients from the highlands of Papua New Guinea, in some of whom the reaction was clinically severe. This group has already been the subject of previous reports ${ }^{8,9}$ though so far its histology has not been described. We have taken the opportunity to make a brief comparative study of the variant forms of ENL and their relationship to certain ethnic groups.

\section{Patients}

\section{Papua New Guinea group}

The patients were seen at Togoba Leprosy Hospital, near Mt Hagan, which serves an ethnically compact population of New Guineans in the eastern and western highlands. The study was a prospective investigation of secondary amyloidosis and ENL, and the patients were to some extent selected as being potential candidates for ENL. Although one of the objects of the study concerned the effect of colchicine, none of the patients was on this drug at the time of biopsy. Only a few were on clofazimine, and steroids were reserved for the severest reactions.

Clinically the reaction pattern of these patients differed from those in Sepik River Area (seen at Aitape). Among those at Togoba were some with small discrete ENL lesions of the classical type which lasted 2-4 days. A larger number produced large tender coalescent areas of deep panniculitis which were hot to touch and had the appearance of peau d'orange. They involved the extensor surfaces of arms and thighs, and also the buttocks, and they lasted many days or weeks. In spite of their severity the skin lesions remained intact, and suppuration was not observed. Unlike the patients with ENL at Aitape, these highland patients rarely developed iritis, arthritis or orchitis; but they had high fever and felt unwell.

Sixty-three biopsies were received from 55 patients with LL or BL leprosy. Of these 41 were initial biopsies taken in the clinically non-reacting state, 22 were taken during a subsequent reaction. The biopsies were processed and examined in London. 
Mexican group

Eighteen biopsies of Mexican patients with ENL were available for study and also, for comparison, 13 biopsies of Lucio's reaction. They were obtained and processed at the Los Angeles County/University of Southern California Medical Center. The patients had not received anti-inflammatory drugs.

\section{Malaysian group}

Biopsies were available from 25 patients with LL leprosy and ENL seen during a 7-year period at the Medical Research Council Unit at Sungei Buloh, Malaysia. Four were included in a previous report. ${ }^{6}$ Of the 23 whose racial origin was known 18 were Chinese, 2 Malay, 3 Indian. Owing to the chronic nature of the reaction some of the more severe cases had been partially immuno-suppressed with steroids. The biopsies were processed and examined in London.

\section{Miscellaneous group}

For comparison with these three ethnically fairly distinct groups, 12 miscellaneous biopsies of ENL lesions were examined from patients from various other parts of the world who were seen in London. They were not receiving anti-inflammatory drugs.

The biopsies in these four groups were all unselected except for the exclusion of histologically trivial cases. All the biopsy specimens extended down to the subcutis. They were processed routinely and stained with haematoxylin-eosin and a modified Fite stain. Special stains were used in selected cases.

\section{Results}

\section{ENL in Papua New Guinea}

Of the 22 biopsies of clinical reaction sites, the reaction histologically was of the ENL type in 20. Of these 20, 3 were the classic non-necrotizing form of ENL associated with neutrophil infiltration in the subcutis or in and around a lepromatous granuloma, described below. The cases identified clinically as 'classical' were among these. The other 17 reactions in this group consisted of ENL of the type that involves primarily the dermal connective tissue. In addition, surprisingly, clear histological signs of ENL were found in 17 of the 41 clinically non-reacting biopsies, 1 classical, 16 of the dermal type.

Thus there were in all 33 cases of ENL of the dermal type, though only 17 of these were clinically reactive. Of the 33 cases 7 were histologically acute inflammatory, 5 were transitional and 21 were in a chronic, fibrosing, stage. All the acute cases were clinically reactive, but 3 transitional cases and 13 of the 21 
chronic cases were clinically non-reacting, despite quite dramatic histological abnormalities in some of them. All these dermal ENL reactions were in patients of the LL type, and they presented no unusual features apart from the reaction, either histologically or bacteriologically.

The acute stage was characterized by severe extra-cellular oedema of the connective tissues of the dermis, associated with degenerative changes in the collagen and elastosis (Fig. 1). In some areas degeneration had progressed to



Figure 1. Acute ENL of the 'dermal' or connective tissue type. Severe degeneration of collagen with some oedema. Note the absence of polymorphs and granuloma. H\&E. $\times 200$.

fibrinoid necrosis (Fig. 2). The most acutely affected areas were infiltrated by primitive young fibroblasts with large pale nuclei which were not far removed morphologically from mesenchymal cells (Fig. 3), and in these areas eosinophils were sometimes present. These changes were most marked in the deep and midzone of the dermis. In the superficial zone there was only a generalized proliferation of swollen young fibroblasts in the interstices of the collagen bundles, without disturbance of the collagen. In parts of the lepromatous granuloma and in the subcutaneous fat generally there was oedema and an infiltrate of lymphocytes, mononuclear cells, plasma cells and a few polymorphs. A similar inflammatory reaction affected the capillaries and arterioles, whose walls were greatly swollen some cases. There was little fat necrosis. In only two cases were there aggregates of polymorphs as in classical ENL, one in the subcutis, the other in the mid-dermis.

The transitional or subacute lesions were marked by the presence of small foci of fibrinoid change and infiltration of fleshy young fibroblasts, and in 


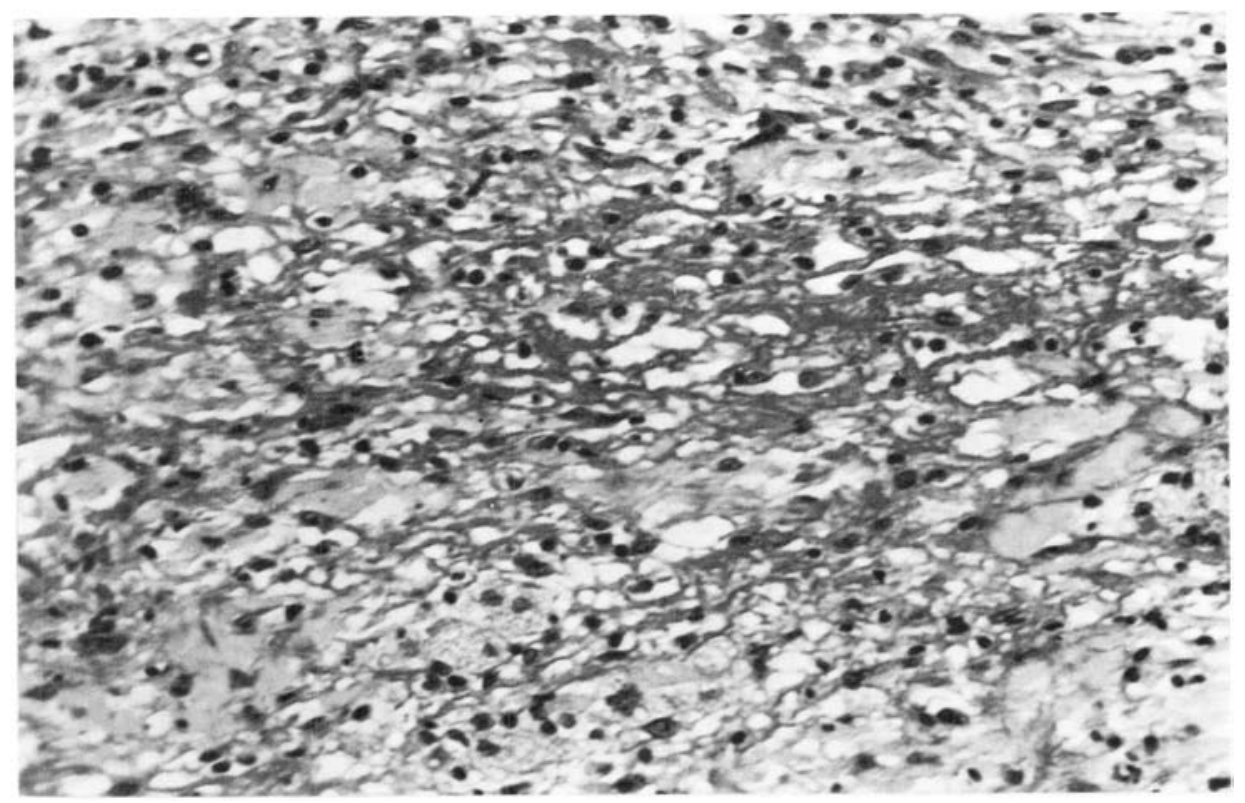

Figure 2. Acute dermal ENL. Fibrinoid necrosis. H\&E $\times 400$.

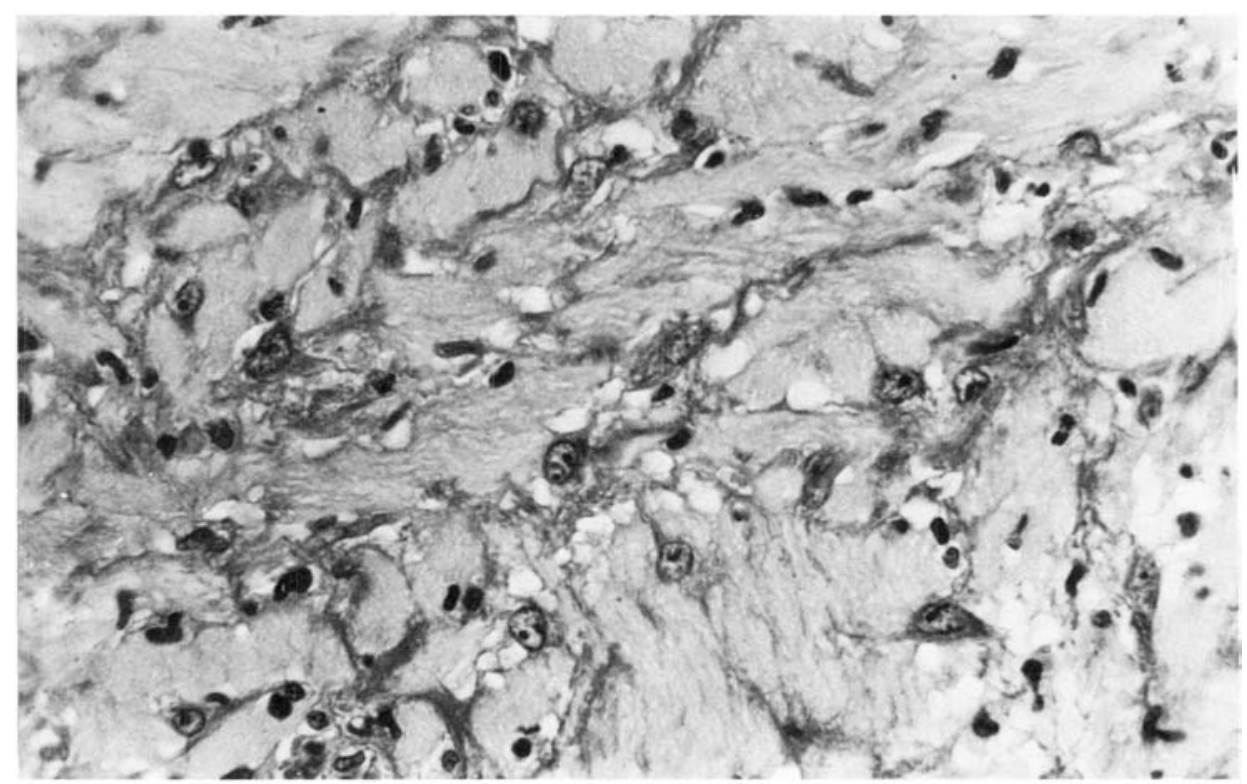

Figure 3. Acute dermal ENL. Influx of primitive young fibroblasts and some oedema. H\&E. $\times 625$.

other areas by a heavy proliferation of more mature fibroblasts, sometimes associated with new capillary formation, which tended to invade the 
lepromatous granuloma (Fig. 4). Elsewhere, especially on the periphery or in the subcutis, there might be course bands of collagen and fibrocytes which resembled a keloid (Fig. 5), though this development was more typical of the chronic fibrosing stage. There was no clear-cut demarcation of the two stages.



Figure 4. Subacute dermal ENL. Proliferation of fibroblasts and some new capillary formation. H\&E. $\times 250$.

In the early chronic as in the subacute stage, chronic vasculitis of greatly swollen arterioles was a conspicuous feature in a few cases (Fig. 6). In the dermis generally oedema had not completely subsided, and plasma cells and mast cells were always present, in variable numbers (Fig. 7). Plasma cells, often quite numerous, were found in dermis as well as the granulomatous areas. The latter were often infiltrated also with lymphocytes, and in two cases numbers of polymorphs were present associated with necrosis in the centre of the granulomatous mass. In the later lesions the lymphocytes and polymorphs had disappeared though some plasma cells and mast cells persisted.

\section{ENL in the Malaysian, Mexican and Miscellaneous groups}

All the patients were classified as LL. Despite the points of difference the reactions in the three groups presented a sufficiently homogeneous histological picture to be considered together, and they shared in common most of the 




Figure 5. Chronic dermal ENL (or periphery of subacute stage lesion). Coarse fibrosis resembling a keloid and extending into the subcutis. H\&E. X 120.

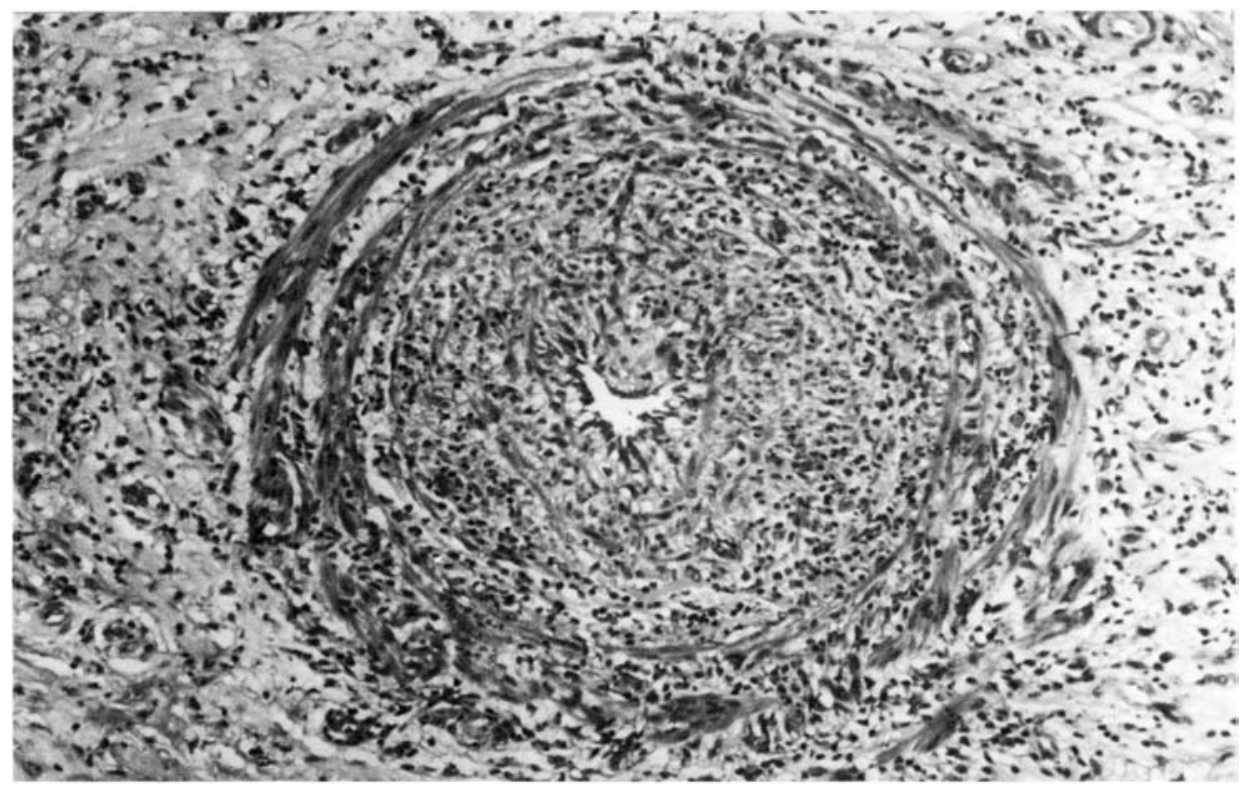

Figure 6. Chronic or subacute dermal ENL. Severe chronic vasculitis in a greatly swollen blood vessel. H\&E. $\times 150$. 


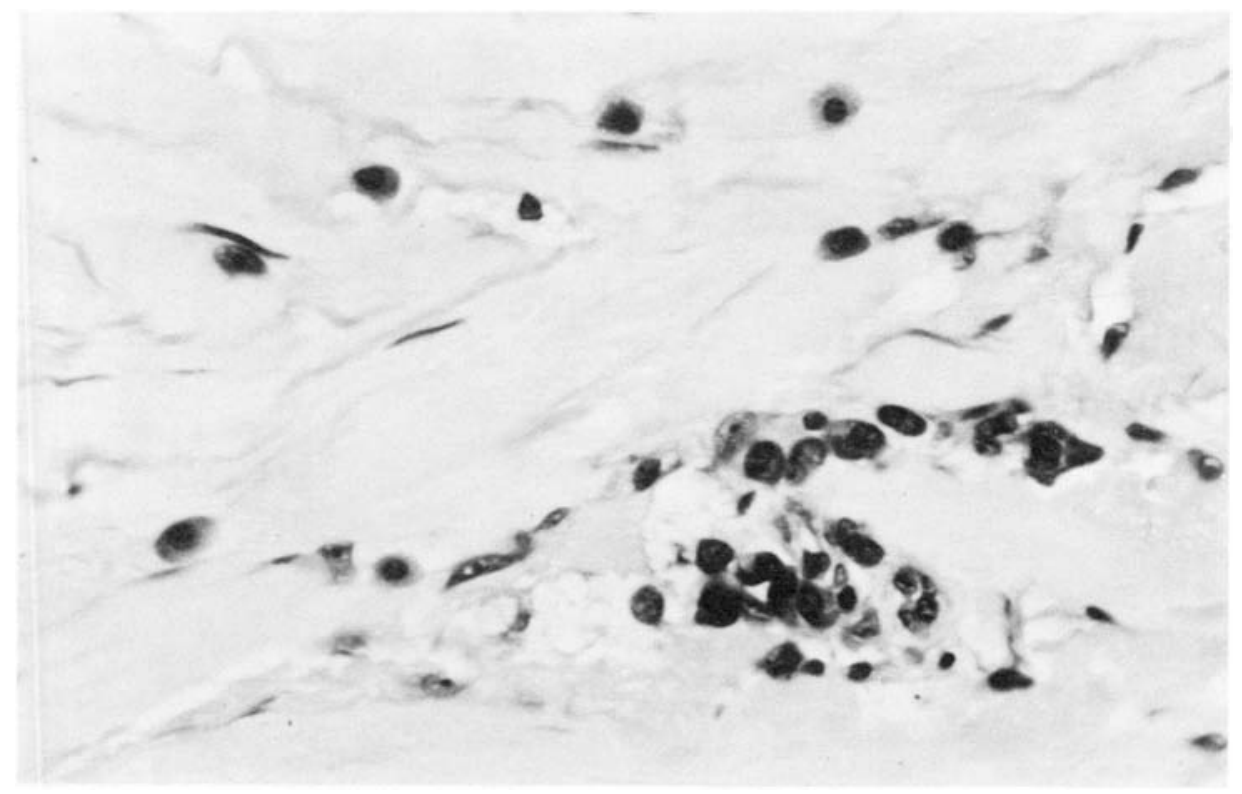

Figure 7. Chronic or subacute dermal ENL. Oedema of dermis with plasma cell infiltrate and increase of mast cells. H\&E. $\times 500$.

features commonly associated with ENL. The groups were found to be comparable in regard to the character of the neutrophilic and lymphocytic infiltrate, the irregular incidence of vasculitis and the range of the indices which reflected the numbers and morphology of bacilli. However, marked differences were noted as to the anatomical site of the most intense inflammatory reaction and the amount of oedema in the superficial dermis.

The distribution of the main sites of the inflammatory reaction is summarized in Table 1. In both Mexicans and the miscellaneous group it was

Table 1. Primary site of inflammation in three groups of patients with ENL

\begin{tabular}{lccc}
\hline & Mexican (18) & Miscellaneous (12) & Malaysian (25) \\
\hline Subcutis and deep dermis & 15 & 9 & 2 \\
Deep and superficial dermis & 3 & 3 & 15 \\
Superficial dermis only & 0 & 0 & 8 \\
\hline
\end{tabular}

located predominantly in the subcutis and deep dermis. Occasionally it was equally severe in the superficial dermis, but the superficial dermis never had an inflammatory reaction more intense than that seen in the deep dermis or subcutis. In contrast, among Malaysian patients the reaction was characteristically more superficial. The deep dermis and subcutis was the site of the most severe inflammatory reaction in only 2 of 25 patients (Figs. 8 and 9). Oedema of the 


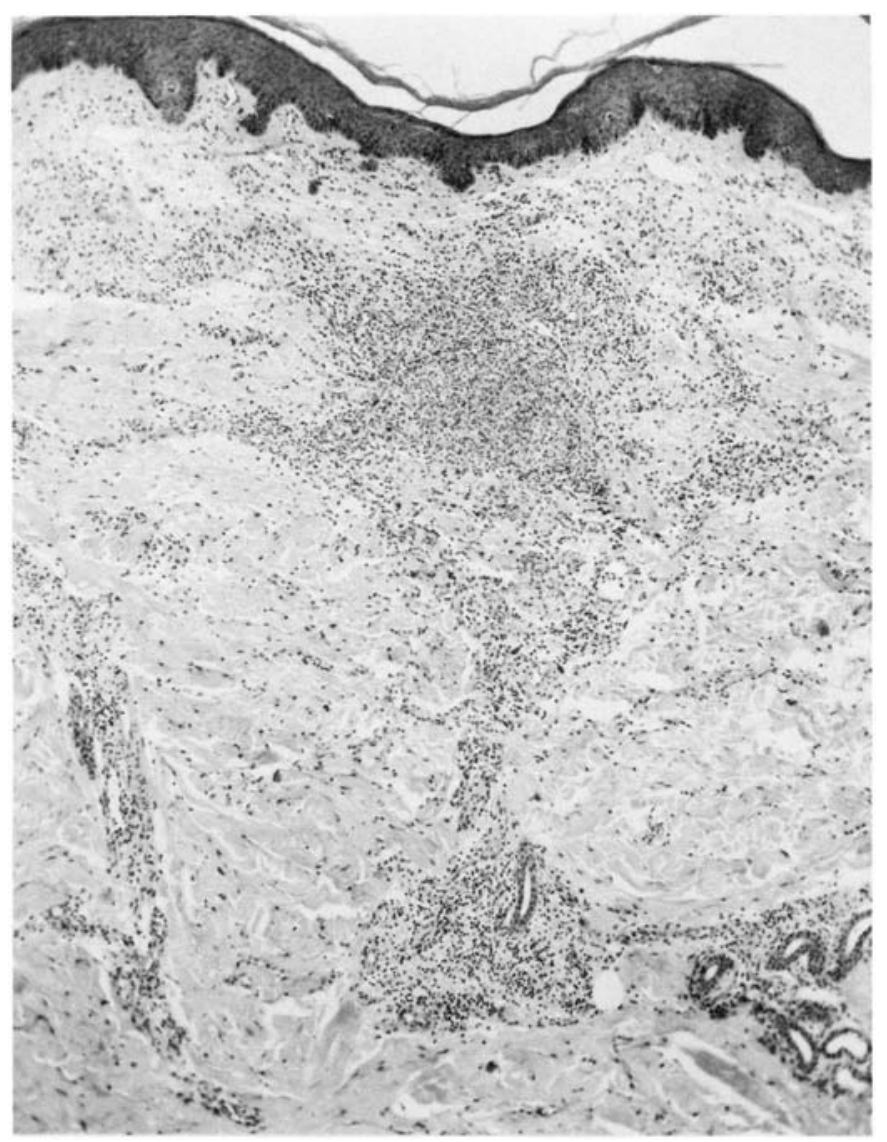

Figure 8. ENL (Malaysia). The reaction involves the granuloma, not the dermis; even in a non-necrotizing case it is predominantly in the superficial zone. H\&E. $\times 20$.

superficial dermis was well developed only among Malaysian patients and at times it could be severe (Fig. 10).

Complete necrosis of a portion of granuloma was seen in one Malaysian case, and small areas of fibrinoid necrosis in a few. There was no ulceration or vesiculation. Three of the lesions appeared to involve granuloma in a wedgeshaped area radiating from a point in the subcutis to an arc of epidermis. Heavy lepromatous involvement of small arteries in the subcutis was noted in some cases, but vasculitis in these vessels was not marked though it was often seen in the smaller vessels of the mid-zone.

\section{Lucio's reaction and necrotizing ENL}

Lucio's reaction was distinguished from the potentially necrotizing ENL of Malaysians by a number of features. Ischemic necrosis of the epidermis and superficial dermis (Fig. 11) was found in 11 of 13 patients with Lucio's 


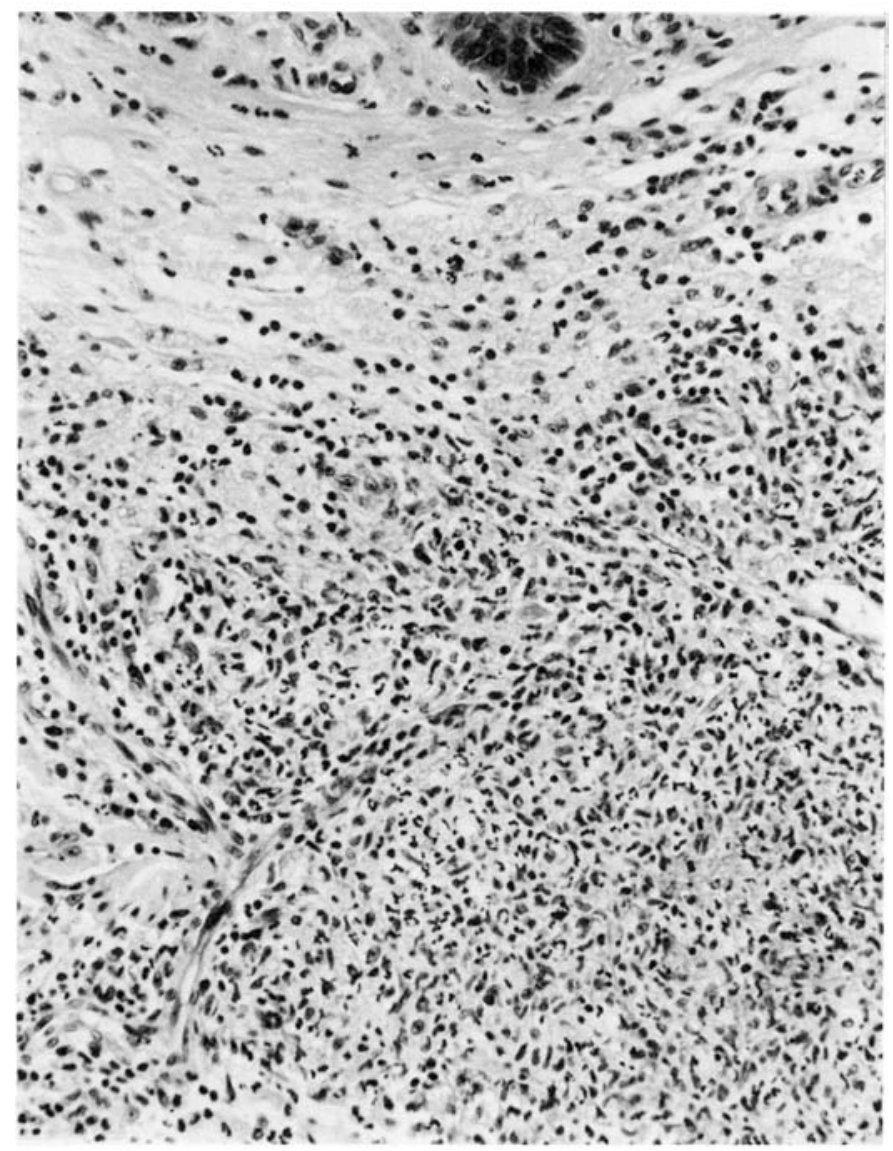

Figure 9. ENL (Malaysia). Detail of Fig. 8. The reaction is of the classical type, with a polymorph infiltrate. H\&E. $\times 150$.

reaction but in none of the 25 Malaysians with ENL, even in the presence of severe oedema. Oedema of the superficial dermis was not a prominent feature in any case of Lucio's reaction, unlike ENL in Malaysia (compare Figs. 11 and 10). Lucio's reaction was characterized by a sparse inflammatory response (Fig. 11). Some neutrophilic reaction might occur, particularly on the border between the viable and infarcted tissue, as in a myocardial infarction. In none of the 13 patients with Lucio's reaction was the neutrophilic reaction ever as well developed as what was regularly found in ENL of Malaysians (compare Figs. 11 and 8).

Other markers of Lucio's reaction not found in Malaysian ENL included comparatively poor development of granulomas in the superficial dermis, prominent endothelial proliferation and abundant AFB in endothelial cells. In areas of endarteritis ENL lesions also showed abundant AFB but these areas were more localized. 




Figure 10. ENL necrotisans (Malaysia). Severe oedema is the main feature of this reaction, which is predominantly superficial. H\&E. X 120 .

\section{Discussion}

The reaction encountered in the highlanders of Papua New Guinea appears to be almost unique, despite the occasional finding of the same sort of reaction in a milder form in patients elsewhere. ${ }^{7}$ The involvement of the connective tissues ranged so far beyond the confines of the granulomatous masses that it was impossible to decide to what extent, if at all in some cases, it was centred on the granuloma which constitutes the lesion of lepromatous leprosy. To a less extent the connective tissues of the dermis are involved in reversal reactions. ${ }^{7}$ Multiple autoantibodies have been observed in patients with leprosy and particularly in those at the lepromatous pole. In the New Guinea leprosy population, antibodies to collagen were detected with the highest prevalence in 


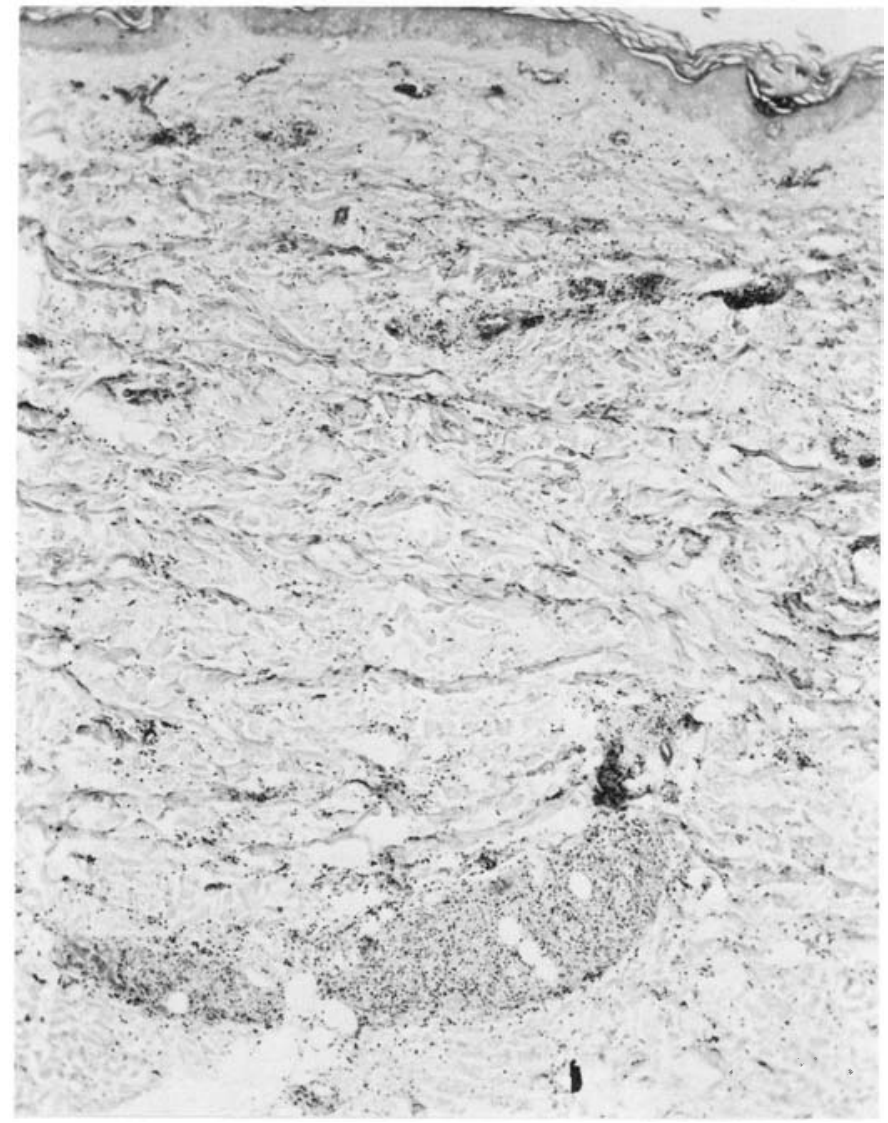

Figure 11. Lucio reaction. There is ischaemic necrosis of the epidermis and subepidermal zone without much oedema or cellular infiltration. H\&E. $\times 20$.

LL patients. ${ }^{10}$ It is unclear whether this was due to the disturbance of collagen, or whether these antibodies were actually augmenting the ENL reaction. In the presence of large amounts of mycobacterial antigens, acting as a local adjuvant, it may be that these antibodies are involved with the pathogenesis of the severe dermal reaction.

The escharotic, haemorrhagic or vesicular type of ENL found in parts of south-east Asia is histologically recognizable as ENL despite atypical features. Selected cases have already been described. ${ }^{5,6}$ The contribution of the present study has been to show that in an unselected series of cases from Malaysia the atypical features (the primary involvement of the superficial zone of the dermis and the severe oedema) present a fairly constant pattern. The superficial distribution was a feature of even mild reactions. Why this should be so is not clear, though the superficial distribution helps to explain the tendency of this form of reaction to become necrotic. Harter and $\mathrm{Kim}^{5}$ refer to a deep, underlying panvasculitis in the subcutis. We could not confirm this, possibly because 
our biopsies did not go deep enough into the subcutis, or because of the partial immunosuppression in some cases. Nevertheless, this observation would be in keeping with the occasional finding of wedge-shaped involvement of the skin with ENL in the Malaysian patients, which was presumably related to a large deep vessel. Furthermore, it may be noted that the finding of immunoglobulin in the vessel walls in ENL has been reported in Malaysian patients, ${ }^{11}$ but not in those from Mexico, ${ }^{12}$ Columbia $^{13}$ or immigrants to New York City. ${ }^{14}$

The Malaysian type of ENL was found to differ distinctively from Lucio's reaction. This is a confirmation of previous reports, ${ }^{5,6}$ and it is also the only direct comparison of these two types of reaction. It was also found that when ENL, as opposed to Lucio's reaction, occurred in Mexican patients it was of the classical deep node type.

From the foregoing conclusions it would appear that ENL is by no means a uniform reaction, and that its form may be influenced by ethnic factors. Some of the confusion that formerly surrounded the classification of leprosy was at one time attributed to ethnically different disease patterns. It is now accepted that these differences are due mainly to variations in the position of ethnic groups within the immunological spectrum. In a previous study we suggested that the predisposition of Mexican patients to develop the Lucio type of reaction might be due to an ultra-low immune level. ${ }^{15}$ By contrast, Malaysian patients who develop ENL are mainly of the sub-polar type of leproma, a form which was first described from Malaysia. ${ }^{16}$ Another factor that might influence the form of a reaction would be the size of blood vessel involved in the vasculitis and immune process. ${ }^{15}$ But neither of these factors appears to be relevant to the ENL reported here from New Guinea. If some of the predisposition to different patterns of ENL is directly due to ethnic factors, they would presumably be mediated by the HLA system. There is an association between B27 and immune complex diseases, especially those of which iritis is a feature. Iritis is a point of distinction between the classical and New Guinea (dermal) form of ENL. Although ENL is attributed to immune complexes, ${ }^{11}$ these are more likely to be extravascular, ${ }^{17}$ not circulating as originally proposed.

ENL and Lucio would appear to represent a complex of reactions in which Lucio is perhaps the most distinctive clinically and the most specific ethnically. Fundamentally the dermal form of ENL may prove to be more disparate. The inter-relationships of the complex are as yet no more clear than the mechanisms at work.

\section{Acknowledgements}

The Togoba study was made possible by the cooperation of Dr Steve R Smith, Medical Superintendent, and his staff at the Leprosy Hospital. For the Malaysian material we are indebted to Dr M F R Waters and Dr J M H Pearson 
and for the miscellaneous (London) material to Dr W H Jopling; we thank them for their cooperation. K P W J McAdam acknowledges the support of Dr R W Hornabrook, Dr D A Russell and Dr R F Anders.

\section{References}

${ }^{1}$ Cochrane RG. In: Cochrane RG, Davey TF eds. Leprosy in Theory and Practice. Bristol: Wright \& Sons, 1964, 331-43.

${ }^{2}$ Pepler WJ, Kooij R, Marshall J. The histopathology of acute panniculitis nodosa leprosa (erythema nodosum leprosum). Int J Lepr, 1955, 23, 53-60.

${ }^{3}$ Job CK, Gude S, Macaden VP. Erythema nodosum leprosum, a clinico-pathogic study. Int $J$ Lepr, 1964, 32, 177-84.

${ }^{4}$ Mabalay, MC, Helwig EB, Tolentino JG, Binford CH. The histopathology and histochemistry of erythema nodosum leprosum. Int J Lepr. 1965, 33, 28-49.

${ }^{5}$ Harter P, Trinh-Thi-Kim-Mong-Don. Formes escarrotiques d'erythema nodosum leprosum et leurs relations avec le phénomène de Lucio. Bull Soc Path Exot, 1962, 55, 993-1025.

${ }^{6}$ Waters MFR, Ridley DS. Necrotizing reactions in lepromatous leprosy; a clinical and histological study. Int J Lepr, 1963, 31, 418-36.

${ }^{7}$ Ridley DS, Wise MJ. Reaction of the dermis in leprosy. Int J Lepr, 1964, 32, 24-36.

${ }^{8}$ McAdam K PWJ, Anders RF, Smith SR, Russell DA, Price MA. Association of amyloidosis with erythema nodosum leprosum reactions and recurrent neutrophil leucocytosis in leprosy. Lancet, 1975, ii, 572-6.

${ }^{9}$ McAdam KPWJ, Smith SR, Takitaki FF, Serjeantson S. The effect of colchicine on serum amyloid A elevation during erythema nodosum leprosum reactions (abstr.). Int J Lepr, $1979,47,382$.

10 McAdam KPWJ, Fudenberg HH, Michaeli D. Antibodies to collagen in patients with leprosy. Clin Immunol Immunopathol, 1978, 9, 16-21.

11 Wemambu SNC, Turk JL, Waters MFR, Rees RJW. Erythema nodosum leprosum: a clinical manifestation of the arthus phenomenon. Lancet, 1969, ii, 933-5.

12 Rea TH, Quismorio FP, Levan NE, Friou GJ. Erythema nodosum leprosum. Arch Dermatol, 1977, 113, 234-5

13 Londono F, Patarroyo ME, de Rueda MMD, Menesses A. Erythema nodosum leprosum. Arch Dermatol, 1977, 113, 234.

14 Fields JP, Abel EA. Immunofluorescent abnormalities in leprosy patients. Arch Dermatol, $1975,111,1164-5$.

15 Rea TH, Ridley DS. Lucio's phenomenon: a comparative histological study. Int J Lepr, 1979, 47, 161-6.

16 Ridley DS, Waters MFR. Significance of variations within the lepromatous group. Lepr Rev, 1969, 40, 143-52.

17 Bjune G. Significance of immune reactions in leprosy. J Oslo City Hosp, 1980, 30, $81-100$. 